\title{
Projeto de Contêineres Metálicos para Instalações Provisórias em Canteiros de Obras
}

\author{
Adriana Gouveia Souza Rodrigo \\ Danielle Gazarini \\ Francisco Ferreira Cardoso
}

\section{Introdução}

Um canteiro de obras é a área de trabalho fixa e temporária, onde se desenvolvem operações de apoio e de execução de uma obra, segundo a Norma Regulamentadora 18 - Condições e Meio Ambiente de Trabalho na Indústria da Construção (BRASIL, 2015). Birbojm e Souza (2002) descrevem instalações provisórias como construções temporárias utilizadas para abrigar as operações de apoio e execução da obra, as quais serão removidas do local após a sua utilização, e que podem ser divididas entre internas e externas. As normas NR 18 - Condições e meio ambiente de trabalho na indústria da construção (BRASIL, 2015) e NBR 12.284 - Áreas de vivência em canteiros de obras Procedimentos (ABNT, 1991) explicitam as áreas obrigatórias de apoio, que devem dispor, no mínimo, de: instalações sanitárias, vestiário, alojamento, local de refeições, cozinha (caso haja preparo de refeições), lavanderia, área de lazer e ambulatório (quando a frente de trabalho possuir mais de 50 trabalhadores); considera-se aqui como instalação provisória as áreas de escritórios.

O mercado oferece atualmente sistemas com maior ou menor grau de industrialização para a execução mais rápida de instalações provisórias, tais como sistema tradicional de chapa de madeira compensado, pré-moldado de madeira, 
contêineres metálicos, construções com estruturas metálicas desmontáveis, prémoldado de concreto e pré-moldado de fibra plástica.

Este capítulo volta-se aos contêineres metálicos para instalações provisórias em canteiros de obras. Tais estruturas são usualmente empregadas como um conjunto de módulos semelhantes, combinados horizontal e verticalmente, formando unidades contínuas, e complementados por estruturas próprias para a circulação de pessoas: escadas e passarelas. Possuem mecanismo de acoplamento e transporte, sendo vedados verticalmente por painéis que admitem diferentes soluções de produtos e preveem aberturas externas e internas, incorporando uma série de sistemas (água, esgoto, energia, iluminação, etc.).

Em geral, os contêineres metálicos possuem dimensões compatíveis com as de uma plataforma de caminhão de circulação em áreas urbanas - da ordem de 2,40 $\mathrm{m}$ de largura por 6,00 $\mathrm{m}$ de comprimento e 2,50 $\mathrm{m}$ de altura-e é usualmente transportado montado em sua configuração tridimensional. $\mathrm{O}$ transporte desmontado exige finalização da montagem nos canteiros de obras, mas reduz os custos do frete. $O$ caminhão usado para esse fim é normalmente equipado com guindaste hidráulico. $\mathrm{O}$ acoplamento dos contêineres na obra não exige pessoal especializado.

Em uma obra, à medida que os diferentes serviços são executados, as instalações do canteiro assumem características e configurações distintas, associadas às diversas fases da obra. Observa-se que, com as mudanças de fases, as instalações provisórias, muitas vezes, são construídas, ampliadas e, posteriormente, demolidas, gerando uma quantidade de entulho e desperdício de material e energia. A identificação dessas fases e das mudanças que ocorrem em cada uma delas, ajuda a compreender a evolução que se espera no desempenho almejado, ajuda também na elaboração de um projeto típico de instalação provisória e como ampliá-lo ou reduzi-lo para acomodar as necessidades de cada fase.

Embora a solução em contêiner metálico alinhe-se fortemente com o conceito de construção industrializada, a realidade mostra que seu uso se dá de forma desordenada, com projetos que seguem a prática usada no emprego de sistemas tradicionais de instalações provisórias.

O objetivo deste artigo é trazer elementos para a criação de um sistema modular em aço para instalações provisórias de obras, apresentando os principais condicionantes de projeto para essas instalações, com base em um programa de necessidades típico para essas estruturas, a fim de possibilitar que a sua configuração se transforme em função das diferentes fases das obras.

A pesquisa, apresentada em Rodrigo et al. (2015), baseou-se em entrevistas e visitas de campo guiadas por um roteiro, que investigou os seguintes itens: identificação da quantidade de trabalhadores por fase das instalações provisórias; caracterização por tipologia construtiva; razão das escolhas das tipologias; programa de necessidades; implantação das instalações provisórias no terreno; procedimento para projeto e responsável pelo projeto; e destinação das instalações provisórias ao final da obra. 
Foram selecionadas cinco grandes empresas construtoras da cidade de São Paulo. Cada uma delas indicou uma ou duas obras para a realização de visitas, totalizando oito obras na cidade de São Paulo, como mostra a Tabela 1. Foram entrevistados cinco responsáveis pelos canteiros de obras, um de cada empresa. Em duas das entrevistas estavam presentes também os representantes das empresas fornecedoras das instalações provisórias. A análise das visitas foi embasada no método de estudo de caso, conforme descrito em Yin (2005).

Tabela 1 - Empresas construtoras e obras correspondentes estudadas.

\begin{tabular}{llllll}
\hline Empresa & Obras & $\begin{array}{l}\text { Área do } \\
\text { Terreno }\left(\mathrm{m}^{2}\right)\end{array}$ & $\begin{array}{l}\text { Quantidade } \\
\text { de edifícios }\end{array}$ & $\begin{array}{l}\text { Número de } \\
\text { andares }\end{array}$ & $\begin{array}{l}\text { Número de } \\
\text { unidades }\end{array}$ \\
\hline A & A1 & 2.500 & 1 & 27 & 260 \\
\cline { 2 - 6 } & A2 & 2.029 & 1 & 27 & 185 \\
\hline B & B1 & 250.000 & 30 & 29 (média) & - \\
\hline D & C1 & 17.462 & 3 & 25 & 246 \\
\hline & D1 & 7.000 & 2 & 25 & 400 \\
\hline D2 & 2.500 & 1 & 16 & 44 \\
\hline
\end{tabular}

Fonte: Rodrigo et al., 2015.

Paralelamente às pesquisas de campo nas obras, foram realizadas quatro visitas de caráter exploratório aos fabricantes de instalações provisórias. O levantamento junto aos fabricantes permitiu que identificássemos os principais fornecedores de componentes e trouxe outras informações relevantes para o desenvolvimento do projeto do módulo metálico em aço.

\section{O Uso dos Contêineres Metálicos nas Diferentes Fases do Canteiro de Obras}

Souza (2000), pensando nas instalações do canteiro de obras, propõe as seguintes fases: 1) movimentação de terra, contenção da vizinhança e fundações; 2) estrutura do subsolo sob a torre e da periferia; 3) estrutura do restante da torre; 4) estrutura e alvenaria; 5) estrutura, alvenaria e revestimentos argamassados; 6) finalização da obra. Em relação à logística interna da obra, Nascimento (2014) propõe quatro fases para o canteiro: 1) mobilização até fundação; 2) fundação e estrutura; 3) início da alvenaria até a conclusão dos revestimentos; 4) acabamentos até entrega. 
Para Souza (2000), a primeira fase, ou seja, movimentação de terra, contenções e fundações, é normalmente marcada pela presença de subempreiteiros donos dos equipamentos, que não necessitam de alojamento, demando poucas construções provisórias no canteiro. Nas fases seguintes, as demandas por espaços de armazenagem e áreas de vivência aumentam, e deve-se pensar nos acessos para materiais, especialmente para realização da estrutura.

Em geral, as empresas visitadas utilizam, em um primeiro momento (fase 1), contêineres simples de aço com fechamentos verticais em chapa de aço galvanizada dobrada para servirem como instalações provisórias. Tal fase pode estender-se até o início da estrutura e, na maior parte dos casos, dura aproximadamente 3 meses.

Após as escavações e primeiras movimentações do solo, há preferência por instalações feitas em madeira (fase 2), que possuem maior flexibilidade em relação à movimentação do canteiro e têm um custo menor, segundo a percepção dos entrevistados. Pode-se dizer que essa fase acompanha o período de obra bruta e estende-se pelo maior tempo possível, em alguns casos até o final da obra.

Em um terceiro momento, já na fase final da obra, isto é, na etapa de acabamentos, é comum que parte das instalações provisórias migrem para dentro da área construída (fase 3- nem todas as obras visitadas consideram essa fase necessária).

Quanto à quantidade de trabalhadores, o total é variável conforme o tamanho da obra em questão. A Tabela 2 mostra a duração de cada fase e o número de funcionários, lembrando que, na tabela em questão, consideraram-se apenas os operários e não os funcionários administrativos.

Tabela 2 - Fases das obras: duração e número de funcionários.

Obras

Fases

\begin{tabular}{l}
\hline Duração (meses) \\
\hline$N^{\circ}$ de funcionários \\
\hline
\end{tabular}

\begin{tabular}{l}
\hline Obra \\
\hline Fases \\
\hline Duração (meses) \\
\hline$N^{\circ}$ de funcionários \\
\hline
\end{tabular}

\begin{tabular}{|c|c|c|}
\hline \multicolumn{3}{|c|}{$\mathrm{A} 1$ e $\mathrm{A} 2$} \\
\hline 1 & 2 & 3 \\
\hline 3 a 4 & $\mathrm{NI} *$ & $\mathrm{NI}$ \\
\hline 10 & 100 & 200 \\
\hline
\end{tabular}

\begin{tabular}{lll}
\hline B1 & & \\
\hline 1 & 2 & 3 \\
\hline 3 a 4 & 18 a 24 & 6 a 12 \\
\hline 35 & $400^{* *}$ & $400^{* *}$ \\
\hline
\end{tabular}

\begin{tabular}{|c|c|c|c|}
\hline \multicolumn{2}{|c|}{ D1 } & \multicolumn{2}{|l|}{ D2 } \\
\hline 1 & 2 & 1 & 2 \\
\hline 1 & 24 & 1 & 20 \\
\hline $\mathrm{NI}$ & 260 & $\mathrm{NI}$ & 175 \\
\hline
\end{tabular}

\begin{tabular}{ll}
\hline $\mathrm{D} 3$ & \\
\hline 1 & 2 \\
\hline 1 & 24 \\
\hline $\mathrm{NI}$ & 420 \\
\hline
\end{tabular}

*NI - Não Informado; **número de funcionários por cada subempreendimento (em 2015, espera-se 3.000 funcionários no total).

Fonte: Rodrigo et al., 2015. 
O faseamento da instalação provisória é necessário, pois as instalações em madeira levam de 1 a 2 meses para serem construídas. Assim, faz-se necessário que algo ainda mais provisório seja construído no decorrer desses meses, e normalmente opta-se por contêineres metálicos simples que ficam prontos para uso em poucos dias ou até mesmo horas.

O engenheiro das obras D1, D2 e D3 manifestou o desejo de que tal faseamento pudesse não ocorrer, já que a instalação provisória da fase 1 representa um trabalho a mais (desmobilizar a instalações da fase 1). Além disso, nos terrenos muito pequenos (comuns na cidade de São Paulo) é difícil de montar a nova estrutura com os contêineres da fase 1 ocupando um espaço considerável, além de representar um risco de segurança desnecessário. O mesmo engenheiro considera desnecessária a desmobilização antes do fim da obra, eliminando, portanto, a terceira fase para as instalações provisórias.

Corroborando com a ideia de permanência de um único sistema de instalação provisória e pensando na logística do canteiro de obras e na economia de recursos, o trabalho de Nascimento (2014) mostra que os contêineres devem permanecer até a fase 2, que compreende as atividades de fundação até as do início da execução dos serviços de alvenaria. Já estão presentes na obra a equipe de estrutura e muitas vezes também de periferia, e funcionários da execução das instalações elétricas e hidráulicas nas lajes. Para Nascimento (2014), o ideal é a permanência dos contêineres até que exista a possibilidade de mudança para o subsolo.

A fase 3 é vista como indispensável pelos engenheiros das obras A1, A2 e B1, por considerarem muito difícil terminar os trabalhos sem a desmobilização da instalação provisória (segundo eles, sempre há algum serviço a ser executado no local utilizado para a construção da instalação provisória, sendo o mais comum a instalação de brinquedos infantis ou áreas de lazer, churrasco, etc.). As obras C1 e E1 já fazem uso das áreas internas do edifício a partir da fase 2. Dessa forma, na obra E1, todas as instalações provisórias são internas e, na C1, apenas o refeitório é interno, durante as fases 2 e 3.

Nas entrevistas, destacou-se que normalmente o que condiciona a necessidade ou não da instalação da fase 3 é o que será construído sob a instalação provisória da fase 2. Assim, por exemplo, quando a instalação é construída sobre um futuro jardim, ela pode permanecer montada até o fim da obra, mas se sob ela houver programada a realização de alguma obra, mesmo que pequena, surge a necessidade de transferência das instalações provisórias para debaixo das lajes.

A possibilidade de existir uma única tipologia de instalação provisória, que permaneça até o fim da obra, é discutida em Said e El-Rayes (2013). Esses autores, porém, destacam que canteiros de obras congestionados, como os terrenos urbanos, frequentemente não têm espaço exterior suficiente para acomodar todas as instalações provisórias, sendo necessária a utilização do interior dos edifícios. 
A Tabela 3 mostra as principais tipologias construtivas de instalações provisórias encontradas. A instalação da fase 2 foi tratada como tipologia construtiva principal, visto ser a que permanece mais tempo na obra. O custo total pode ser dividido por algumas obras (quando a instalação é reutilizada, segundo relato dos entrevistados).

Tabela 3 - Tipologias construtivas das instalações provisórias.

\begin{tabular}{|c|c|c|c|c|c|}
\hline \multirow[t]{2}{*}{ Empresa } & \multirow[t]{2}{*}{ Fase 1} & \multirow[t]{2}{*}{ Fase 2} & \multicolumn{3}{|c|}{ Fase 2 (principal) } \\
\hline & & & Contratação & $\begin{array}{l}\text { Custo total } \\
\left(\mathrm{R} \$ / \mathrm{m}^{2}\right)\end{array}$ & $\begin{array}{l}\text { Custo por } \\
\text { obra }\left(R \$ / m^{2}\right)\end{array}$ \\
\hline A & $\begin{array}{l}\text { Contêiner chapa } \\
\text { dobrada }\end{array}$ & Madeira & Comprada & 325 & 175 \\
\hline B & $\begin{array}{l}\text { Contêiner chapa } \\
\text { dobrada } \\
\text { e madeira } \\
\text { provisório. }\end{array}$ & Madeira & $\begin{array}{l}\text { Fabricação } \\
\text { própria }\end{array}$ & 350 & 350 \\
\hline C & $\begin{array}{l}\text { Contêiner chapa } \\
\text { dobrada }\end{array}$ & Madeira & Comprada & 240 & 240 \\
\hline D & $\begin{array}{l}\text { Contêiner chapa } \\
\text { dobrada }\end{array}$ & $\begin{array}{l}\text { Madeira com } \\
\text { estrutura metálica }\end{array}$ & Comodato & - & 400 \\
\hline$E$ & $\begin{array}{l}\text { Contêiner chapa } \\
\text { dobrada }\end{array}$ & $\begin{array}{l}\text { Estrutura metálica } \\
\text { (sem teto) e PVC }\end{array}$ & Alugada & - & 210 \\
\hline
\end{tabular}

Fonte: Rodrigo et al., 2015.

A tipologia construtiva da fase 3 não consta na tabela, uma vez que envolve o uso temporário de áreas internas do edifício, normalmente se empregando partes das instalações da fase 2, como para compartimentalização de áreas, vasos sanitários, etc.

$\mathrm{O}$ uso dos contêineres foi observado apenas na fase $1 \mathrm{e}$ em todas as obras. $\mathrm{O}$ arranjo característico previu o uso de dois a três contêineres simples, normalmente montados deixando-se uma distância de 2 metros entre eles, sendo esse espaço coberto e utilizado como vestiário, local para pendurar toalhas ou refeitório. O cumprimento da NR 18 - Condições e meio ambiente do trabalho na indústria da construção (BRASIL, 2015), nessa fase, fica comprometido, tendo sido observado a falta de armários, refeitórios improvisados e revestimentos de vestiários inadequados. Outra constatação é o uso de construções sob a forma de aluguel, como no caso dos contêineres, ou sob a forma de comodatos.

O uso do contêiner simples de chapa dobrada, sem tratamento térmico e acústico, não é nem cogitado para a segunda fase (por nenhuma empresa), pois traria um grande incômodo aos trabalhadores. Nessa fase, a estrutura em madeira é considerada mais confortável, ainda que não seja completamente adequada. De 
maneira geral o contêiner simples de chapa dobrada é visto como provisório e, mesmo com o uso de ar-condicionado, não é confortável, segundo os entrevistados.

Contêineres de aço com desempenho superior (sobretudo devido aos vedos paredes e teto - com componentes que o isolam termicamente do ambiente exterior) foram considerados muito caros por todas as empresas entrevistadas. Além disso, as empresas alegam que, caso o contêiner fosse comprado, não haveria local para guardá-lo nos momentos em que ele não estivesse em uso e pagar aluguel para esse fim, durante toda a obra, poderia acarretar um gasto muito elevado.

Todas as empresas citaram o fato da instalação em madeira ter um custo menor que a instalação em aço (com desempenho equivalente). A adaptabilidade das instalações em madeira, embora citada como vantajosa pelos entrevistados, na prática mostrou-se difícil de ser feita.

Outros condicionantes na tomada de decisão para o sistema construtivo foram o serviço de montagem, desmobilização e, em alguns casos, até a transferência para outra obra, serviço que a empresa fornecedora da instalação em madeira oferece. O fornecedor parceiro da empresa " $D$ " disponibilizava inclusive um sistema de manutenção e limpeza diária.

Com relação à destinação das instalações provisórias ao final da obra, ficou clara a vantagem das instalações em aço. Por possuírem vida útil muito maior, podem ser reutilizadas inúmeras vezes apenas com manutenção. Segundo uma das empresas fabricantes de contêiner simples de chapa dobrada, um mesmo contêiner pode ser utilizado até 20 vezes, mediante manutenção. Além do mais, as instalações hidráulicas, tubulações e fiações, se corretamente integradas ao contêiner, podem ser reaproveitadas. Ao final da vida útil, quando a instalação chega a apresentar algum dano estrutural, o contêiner pode ser totalmente reciclado, pois o aço é reaproveitado sem qualquer perda de qualidade. No caso das estruturas e vedações de madeira, embora a reutilização seja possível, nota-se que somente a empresa " $\mathrm{A}$ " tenta viabilizá-la e, segundo a entrevista, nem sempre consegue. Quando consegue, reutiliza somente algumas partes. Nesse tipo de estrutura, ademais, as instalações hidráulicas, tubulações e fiações dificilmente são reaproveitadas.

\section{Condicionantes do Projeto de Contêineres Metálicos}

No levantamento realizado por Rodrigo et al. (2015), identificaram-se outras condicionantes de projeto para as instalações provisórias, típicas da cidade de São Paulo. Entende-se por condicionante de projeto as condições específicas encontradas nas obras visitadas com potencial para tornarem-se diretrizes de projeto: dimensões máximas, organização interna dos ambientes, identificação de necessidades de ampliação, dentre outras. 
Verificou-se que as empresas construtoras, na maioria dos casos, elaboram um projeto diferente para cada obra (com total liberdade de criação das instalações provisórias). Não se aproveita o mesmo projeto nem sequer em casos de terrenos com condições muito similares. Os fornecedores de instalações provisórias para canteiros de obras, igualmente, pouco trabalham com padronizações e inclusive a modulação é precária. Estas condições acarretam um considerável sobrecusto para as instalações provisórias, geração excessiva de resíduos e dificultam a gestão dos canteiros, dadas as inúmeras adaptações que ocorrem no decorrer do período das obras. É marcante a possibilidade de o projeto das instalações provisórias ser padronizado e modular, permitindo alguma customização, mas não a total liberdade, como é feito hoje. Quanto aos módulos de aço existentes, identificou-se que são genéricos e não projetados especificamente para o caso das instalações provisórias em canteiros de obras.

Para o projeto de um sistema modular em aço, antes de tudo, deve-se considerar o programa de necessidades. Observa-se que já existe um programa padrão, sobretudo para as áreas de vivência e higiene, que são obrigatórias pela Norma Regulamentadora 18 - Condições e Meio Ambiente de Trabalho na Indústria da Construção (BRASIL, 2015), pela Norma Regulamentadora 24 - Condições Sanitárias e de Conforto nos Locais de Trabalho, (BRASIL, 1993) e pela NBR 12284- Áreas de vivência em canteiros de obras - Procedimento (ABNT, 1991). As áreas de escritório não são normatizadas e existe uma variabilidade caso a caso, embora sempre estejam presentes pelo menos uma sala de reunião fechada, além de sala para o engenheiro, técnicos e estagiários e sala para o encarregado e almoxarifado.

Observa-se a necessidade de um espaço para treinamento e cursos para os operários, os quais podem ocorrer no refeitório, desde que projetados para atender às duas funções. Deve-se prever instalação de TV de plasma ou aparelho de projeção nesses locais. O projeto dos módulos metálicos deve prever instalação de equipamentos antirroubos e antivandalismo. Outra boa prática é o uso de pintura externa com possibilidade de marketing (ser adesivada, por exemplo).

Casos especiais, como a obra B1, em que existe inclusive a necessidade de sala blindada, auditório e uma cozinha industrial completa, não devem ser considerados na elaboração do projeto dos módulos para canteiros (devem ser sempre tratados como projetos especiais).

O projeto do sistema modular em aço para canteiros de obras deve prever ações voltadas à economia de energia e água, tais como: chuveiro com aquecimento solar; reuso de águas e uso de água da chuva; depósito de lâmpadas fluorescentes queimadas; cisternas para captação da água da chuva; aproveitamento da iluminação natural; e vedos que possibilitem a redução da carga térmica (o que não é viável utilizando-se apenas o aço nas vedações - deve-se prever vedações verticais e coberturas aptas a receber revestimentos internos ou externos). 
A funcionalidade dos espaços construídos, melhor aproveitamento dos espaços evitando a ociosidade, área de circulação reduzida e uso de divisórias internas somente quando necessárias são fatores que fazem parte das necessidades das empresas construtoras e devem ser considerados na elaboração dos projetos dos módulos.

Fatores externos como acessos limitados e terrenos pequenos também devem condicionar o projeto dos módulos, já que são circunstâncias comuns à maioria das metrópoles brasileiras. Como normalmente as instalações provisórias ficam confinadas nas áreas de recuo obrigatório, a dimensão desse espaço deve também condicionar a largura dos módulos, e não somente o tamanho do chassi do caminhão que irá transportá-lo, como no caso dos contêineres marítimos.

Para determinação da largura dos módulos, deve-se considerar ainda o tamanho das bobinas de chapas de aço dobradas existentes no mercado, além da modulação de outros componentes.

Outra condicionante é a prioridade que o estande de vendas costuma adquirir na locação do canteiro, restando às instalações provisórias a extensão que sobra do recuo, ou seja, deve-se prever o empilhamento dos módulos, a otimização do uso dos espaços, a redução de áreas de corredor e os espaços multiuso, sempre que possível. Locais destinados a armários devem estar sob ou sobre as mesas, reduzindo a área de piso da instalação dos escritórios.

As ligações com as redes de água e esgoto devem ser únicas, mas possíveis de serem adaptadas à condição e ao posicionamento de cada empreendimento. As entradas elétricas devem ser simples, preferencialmente sob a forma de uma tomada, por exemplo.

O projeto dos módulos para as áreas de vivência e higiene deve considerar, além das normas pertinentes, a estimativa do efetivo mínimo e máximo da obra, bem como as suas fases, para o planejamento das ampliações e adaptações. Por exemplo, módulos para banheiros e vestiários devem permitir ampliações e facilidade de interligação.

Tendo em vista as condicionantes identificadas nas visitas de campo e nas entrevistas, a Figura 1 apresenta um módulo base desenvolvido a partir do programa de necessidades para as áreas de vivência. As cinco configurações apresentadas atendem às exigências normativas, ou seja, tamanhos dos elementos e áreas de circulação. Tais configurações, quando combinadas lado a lado, permitem organizar as áreas de vivências para um número maior ou menor de funcionários. A Figura 2 apresenta três exemplos de combinações dos módulos, com variação no número de funcionários atendidos - 100, 180 e 260 funcionários -, a quantidade e disposição dos elementos também respeitam a normativa pertinente.

A proposta de instalação provisória modular apresentada nas Figuras 1 e 2 buscou reduzir as áreas de circulação e encontrar um tamanho ótimo de módulo base, que proporcione instalações com a menor área possível. 

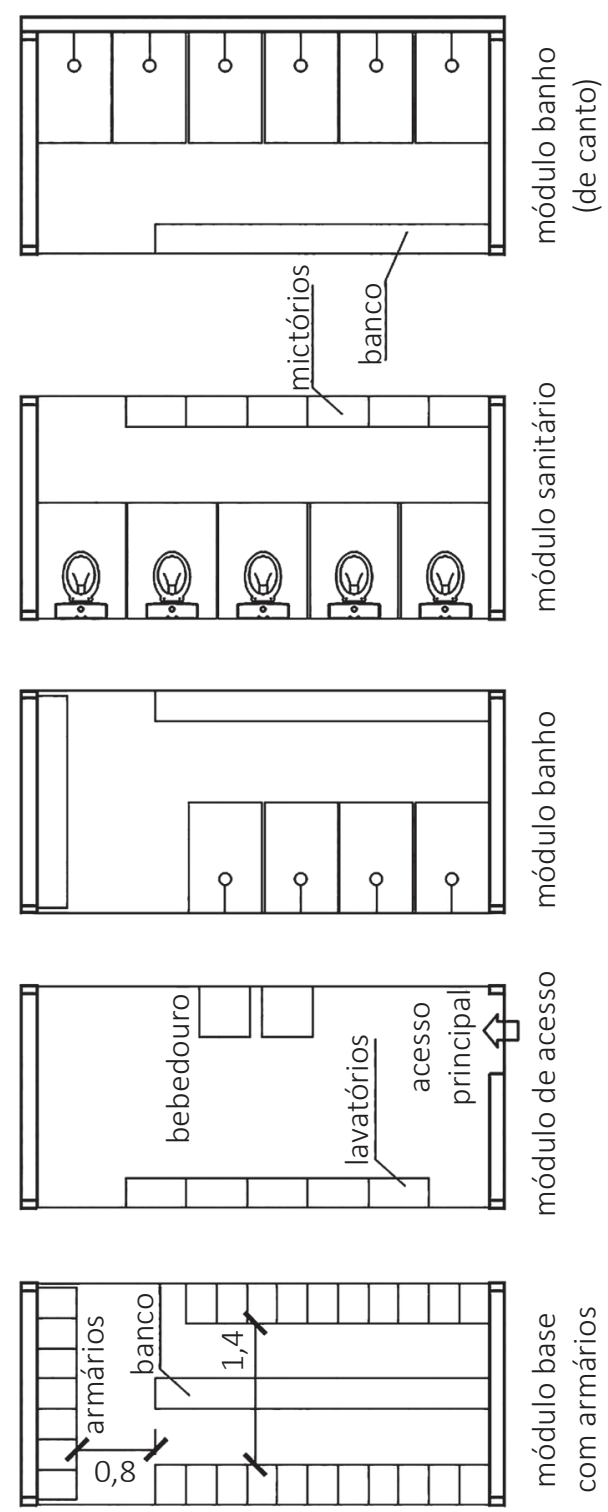

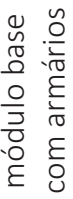

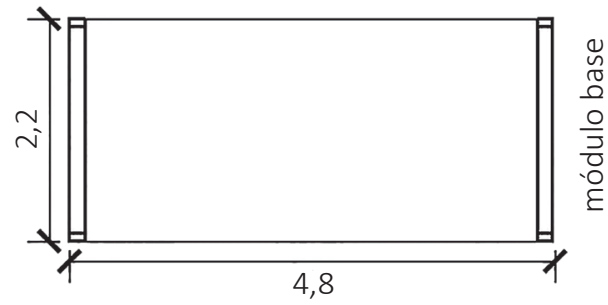

Figura 1 - Módulos para áreas de vivência. 


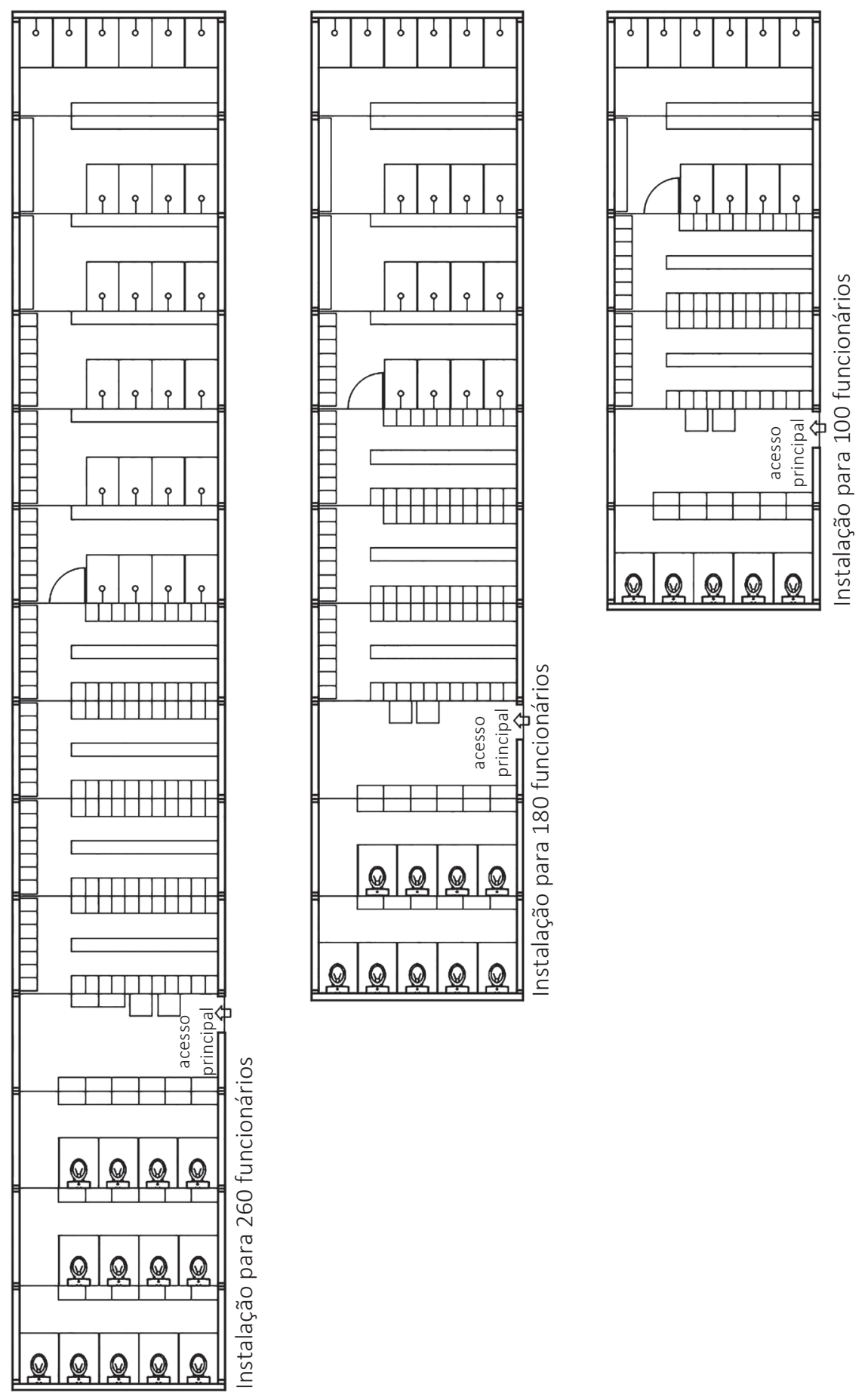

Figura 2 - Módulos combinados - áreas de vivência para 100, 180 e 260 funcionários. 
A Figura 3 apresenta, em caráter ilustrativo, uma proposta de projeto de instalação provisória completa - áreas de vivência e escritórios - feita a partir dos módulos base para um contingente de 100 funcionários. Nesta ilustração, considerouse que o período de almoço será dividido em dois turnos.

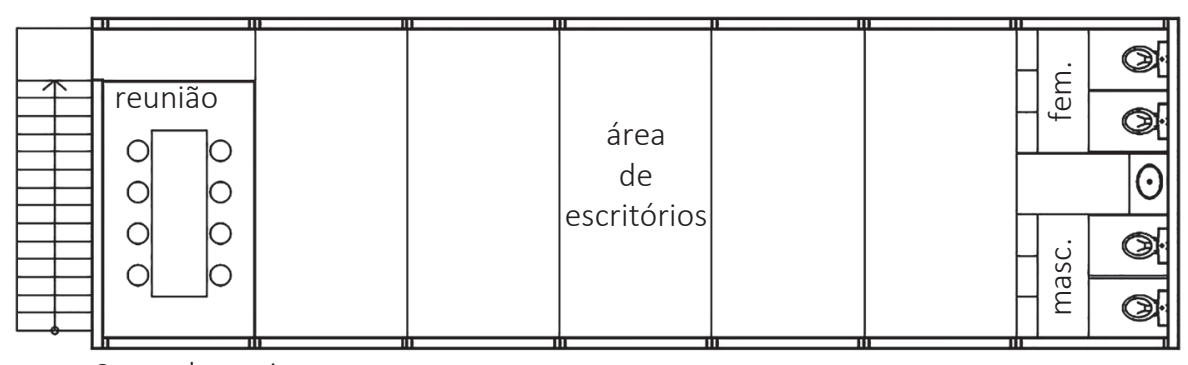

Segundo pavimento

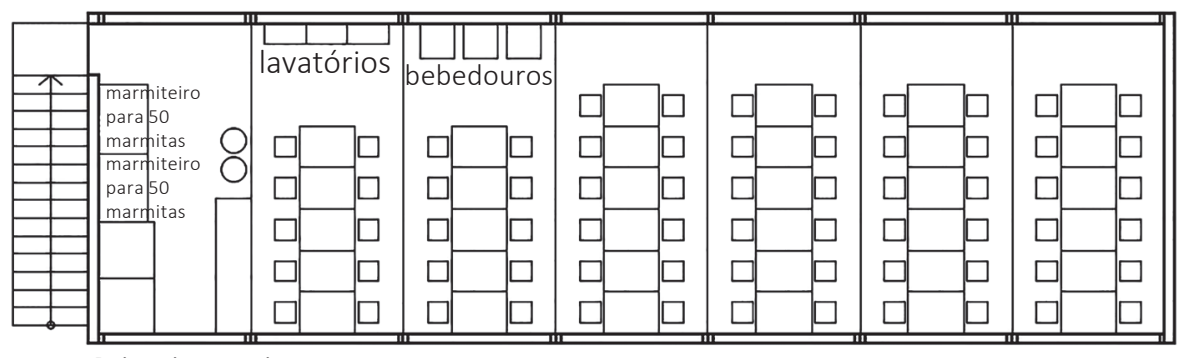

Primeiro pavimento

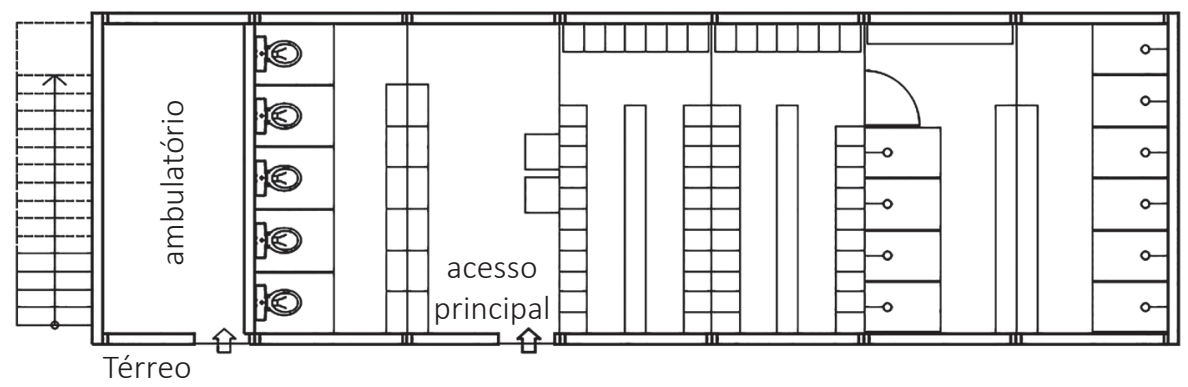

Figura 3 - Planta baixa de instalação provisória: áreas de vivência, refeitório e escritórios para obras com 100 funcionários.

\section{Conclusões}

O capítulo trouxe um estudo de campo que mostrou que as necessidades de instalações provisórias variam em função da fase da obra e, por conseguinte, das tipologias construtivas empregadas. Mostrou ainda que, embora os contêineres de aço sejam atualmente empregados, sobretudo, na fase inicial de uma edificação, quando a 
necessidade de áreas e as demandas para os espaços internos são bastante limitadas, a busca por soluções rápidas, sustentáveis e economicamente viáveis faz com que essas estruturas sejam uma solução capaz de permanecer em outras fases e oferecer um melhor desempenho.

A análise dos dados colhidos nas visitas às obras e aos fabricantes proporcionou a possibilidade de determinar uma instalação provisória típica dos canteiros, sob o ponto de vista da forma (normalmente restrita ao recuo obrigatório), da funcionalidade (ligação entre os ambientes, conforto ambiental) e das conexões com as redes de infraestrutura (água, esgoto, energia, etc.).

Diferentes autores discorrem sobre modelos computacionais e matemáticos criados para organização dos canteiros de obras, dentre eles pode-se citar Andayesh e Sadeghpour (2013) e Karan e Irizarry (2015). Ao analisar aos resultados desses trabalhos, percebe-se que tratam as instalações provisórias como se pudessem ter qualquer tamanho. Questões como modulação e padronização industrial dos sistemas construtivos dessas áreas pouco são levadas em conta. Existe uma oportunidade de desenvolvimento de trabalhos futuros que juntem as tecnologias computacionais a um modelo padronizado e customizável de instalação provisória.

A criação de um sistema único de instalação provisória em contêiner de aço, que possa ser aproveitado em todas as fases da obra, de montagem rápida e confortável e com a possibilidade de ser reutilizado em outras obras, representa uma necessidade iminente no setor da construção civil. Os módulos metálicos existentes são genéricos e não projetados especificamente para o caso das instalações provisórias em canteiros de obras. Nota-se, dessa forma, uma lacuna de mercado, já que um produto que atendesse às normas e fosse específico para o caso dos canteiros de obras geraria economia de custos, tempo e espaços internos.

\section{Referências}

ABNT (Associação Brasileira de Normas Técnicas). NBR 12.284 - Áreas de vivência em canteiros de obras - Procedimento. Rio de Janeiro, 1991.

ANDAYESH, M.; SADEGHPOUR, F. Dynamic site layout planning through minimization of total potential energy. In: Automation in Construction, v. 31, 2013, p. 92-102.

BIRBOJM, A.; SOUZA, U.E.L. Construções temporárias para o canteiro de obras. Boletim Técnico 315. São Paulo: EPUSP - Departamento de Engenharia de Construção Civil, 42p. 2002.

BRASIL. Ministério do Trabalho e Emprego. Norma Regulamentadora 18 (NR-18): Condições e meio ambiente de trabalho na indústria da construção. 2015. Brasília-DF. Disponível em: <http://trabalho.gov.br/seguranca-e-saude-no-trabalho/normatizacao/ normas-regulamentadoras/norma-regulamentadora-n-18-condicoes-e-meio-ambientede-trabalho-na-industria-da-construcao>. Acesso em: jan. 2017. 
BRASIL. Ministério do Trabalho. Norma Regulamentadora 24 (NR-24): Condições Sanitárias e de Conforto nos Locais de Trabalho, 1993. Disponível em: <http://trabalho.gov.br/images/ Documentos/SST/NR/NR24.pdf>. Acesso em: jan. 2017.

KARAN, E.P.; IRIZARRY, J. Extending BIM interoperability to preconstruction operations using geospatial analyses and semantic web services. In: Automation in Construction, v. 53, 2015, p. 1-12.

NASCIMENTO, R.R. Logística na construção de edifícios. Estudo de caso em grande construtora. Monografia (especialização) - Tecnologia e Gestão na Produção de Edifícios. São Paulo, Universidade de São Paulo, Escola Politécnica, 2014.

RODRIGO, A.G.S.; GAZARINI, D.; CARDOSO, F.F. Condicionantes de projeto para as instalações provisórias em canteiros de obras na cidade de São Paulo. In: Proceedings of the Latin-American and European Conference on Sustainable Building and Communities: Connecting People and Ideas. July 21th - 24th, 2015, Guimarães, Portugal. Universidade do Minho and others. pp. 2495-2504.

SAID, H.; El-RAYES, K. 2013. Optimal utilization of interior building spaces for material procurement and storage in congested construction sites. In: Automation in Construction Journal, n. 31, 2013, p. 292-306.

SOUZA, U.E.L. Projeto e implantação do canteiro. São Paulo: O Nome da Rosa. 92p., 2000.

YIN, R.K. Estudo de caso: Planejamento e métodos. Tradutor Daniel Grassi. 3. ed. Porto Alegre: Bookman, 2005. 